\title{
On Ship Ventilation as a Department of Naval Hygiene
}

John D. MacDonald Retired M.D., F.R.S.

To cite this article: John D. MacDonald Retired M.D., F.R.S. (1895) On Ship Ventilation as a Department of Naval Hygiene, Royal United Services Institution. Journal, 39:209, 721-732, DOI: $10.1080 / 03071849509416164$

To link to this article: http://dx.doi.org/10.1080/03071849509416164

册 Published online: 11 Sep 2009.

Submit your article to this journal $₫$

Џll Article views: 3

Q View related articles 5 
Wednesday, May I $5^{\text {th }}, 1895$.

Inspector-General of Hospitals and Fleets, WilliaM H. Lloyd, ... the Chair.

\title{
ON SHIP VENTILATION AS A
}

\section{DEPARTMENT OF NAVAL HYGIENE.}

\author{
By $\mathscr{F} O H N$ D. MACDONALD, M.D., F.R.S., \\ Inspector-General of Hospilals and Fleets R.N. (retired).
}

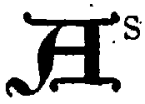

a single lecture on so wide a subject as "Naval Hygiene" would be too desultory in its nature for the present occasion, I thought it would be more profitable to confine our attention to the department of ship-ventilation, which is now of so much importance.

Iniraductory. Remarks.-Although the physical constitution of the atmosphere, its chemical components and their properties, cannot be exhaustively treated here, there are certain preliminary particulars which, if borne in mind, will greatly assist the comprehension of the subject of ventilation, what it is intended to do, and how this is to be accomplished.

I. The atmosphere which surrounds our globe is many (say 45) miles in depth, gradually increasing in density from its outer surface to the surface of the earth, where its pressure is estimated to be as 15 lbs. to the square inch. To a certain extent it follows the rotation of the earth; but meteorological conditions disturb its equilibrium, and give rise to the trade winds, cyclones, and other ä̈rial currents. The component gases of the atmosphere are by these means mechanically mixed. but their more intimate blending is effected by the law of the diffusion of gases. Moreover, the respiration of animals is so beautifully complementary to that of plants, that the waste of one becomes the pabulum of the other, which is, at least, one factor in the great uniformity of composition everywhere observable in common air. It is curious also to observe that while the food of plants is primarily inorganic, that of animals is necessarily composed of organic matter; but opposite conditions obtain in regard to their respiratory processes. Thus compound substances supply the respiration of plants, while simple elements in mechanical mixture are essential to the respiration of animals. The presence of Lord Rayleigh's new gas, argon, would make some little alteration in the general proportion of the constituents; but the old form may still be taken for practical purposes, i.e., oxygen $20^{\circ} 96$ vols., nitrogen $79^{\circ} 04$ vols., and carbonic acid 4 per 1,000 . 
Of the two more essential constituents (o.xygen and nitrogen), nitrogen exists in larger amount, its proportion to the oxygen being nearly as four to one.

This proportion is wisely arranged for, just as with an additional amount of oxygen combustible matter would burn more rapidly, so the vital processes would become more active, and we would live all the faster, if the expression may be allowed. The large dilution of oxygen with nitrogen adds materially to the bulk of the atmosphere, effecting a wider diffusion of light and tending to equalise the influence of heat under the varying conditions of scason and climate.

Carbonic acid occurs in the atmosphere as a product of combustion, respiration of animals, and decay of various kinds. It has also a terrestrial service, as in Pyrmont, the "Grotto del Cane," and in coal measures under the name of "choke damp."

When ill-effects result from the incautious burning of charcoal in confined apartments, carbonic oxide would appear to be the special agent in operation. The inhalation of pure carbonic acid induces immediate apnoea, by causing spasmodic closure of the glottis. Nevertheless, a fatal issue is still brought about by carbonic acid, but the source, strange to say, is from within the system itself.

It is commonly supposed that such an impregnation of atmospheric air, as will not be quite sufficient to stop combustion or extinguish flame, may be inhaled with impunity by man, hence the precaution of lowering a light in pump-wells, pits, and such places, to apply this test practically. But it is now well known that a candle may burn in an atmosphere which would quickly bring about insensibility and serious results if inhaled unwittingly.

It is certain, however, on the other hand, that artisans are frequently obliged to resort to expedients to keep their candles alight when at work in the lower parts of ships, as in double bottoms, etc. But this only shows that man may live for some short time where it is difficult to maintain the combustion of flame.

Aqueous vapour exists in the air in very variable amount, being under the influence of climate, temperature, the direction of the winds, and other local conditions; and inasmuch as a perfectly dry atmosphere would prove fatal to both animals and plant, it must be included amongst the necessary components of wholesome air.

Ammonia is evolved by the putrefaction of nitrogenous organic substances. It is also usually absorbed by rain water while falling to the carth, and this would appear to be one of Nature's means of removing it from the atmosphere and giving it to the soil for the benefit of plant life. In any case, it can only be said to be present in comparatively small amount.

The salts of the ocean are known to pass up in the air in considerable quantity by the rapid evaporation of finely-divided spray. It is frequently found that books and other things of an absorbent description on board ship become imbued in the lapse of a little time with the chloride of sodium, etc. 
Organic matlers, whither in simple suspension or more complete diffusion, are often present in the atmosphere. Thus, we find the débris of animals and plants, or whole organisms, ranging from those visible to the naked eye to those requiring the highest microscopic powers for their recognition. I have myself found gelatinous fronds of living bacteria attached to floating fibres of wool and cotton, and the same is quitc true even of the ground air, which is an atmosphere still below that in which we live. Many curious parts in connection with this interesting subject sustain the so-called " germ theory" of specific diseases, and the ample provision afforded for their dissemination and spread to incredible distances. Now, as organic matter-must, sooner or latter, become oxidised, both in air and in water, fresh air must be regarded as the best disinfectant, dispelling noxious principles in an attenuated form, in a manner quite analogous to that by which water washes away those of a grosser kind. Here, then, we are afforded a clear view of the nature and necessity of an efficient ventilation, but this will be practically illustrated in the three following cases:-

1. Let a man be confined in a close chamber; having no communication with the external air, at every expiration a volume of moist, warm air, charged with carbonic acid and deprived of much of its oxygen, will ascend to the ceiling. But after awhile, having suffered sufficient condensation, it will descend again towards the floor, and it is easy to see that a repetition of this process would soon render the air irrespirable, ${ }^{1}$ and a fatal issue incvitable.

2. If a single opening were made in the upper part of the same chamber we should only delay the process, for, although diffusion would be favoured, to a certain extent, in this way, the amount of carbonic acid would steadily increase, and the available oxygen would be exhausted, when life could no longer be sustained.

3. Let two distinct openings be made, and a trifling circumstance will convert one of them into an up-take, while the other will convey downwards a fresh supply of air to meet the requirements of respiration.

These conditions may be well illuştrated by taking an unstoppered decanter or water-bottle, and observing the effect produced on holding a small wax taper attached to a wire, near the bottom. The little flame will burn brightly for a short time, when it will be seen to grow gradually more and more dim, until it dies out altogether. To complete this experiment, if a slip of cardboard is placed in the neck of the bottle, so as to form a vertical septum, the taper being then introduced will burn to the end. The heated air, charged with carbonic acid, will ascend through the neck on one side of the card, while a current of pure air will continue to descend on the other, and support the combustion of the flame. A central tube, equivalent to a circular septum, will answer the same purpose. The former example would represent Mr. Watson's patent, and the latter that of MICKinnell.

About the middle of the last century, similar conditions were made apparent to Mr.-Sutton, a brewer, in the case of his own drawing-room,

1 When twenty-eight parts of the oxygen of the contained air are consumed. 
which was large enough to be supplied with three fire-places. He observed that, when a fire was lighted in one of these, the ascensional and extractive force developed was attended with a downcast in the two other chimneys. MIr. Sutton at once grasped the idea, and applied it to the ventilation of ships, utilising the galley fire as an extracting force, and establishing a tubular communication between the ash-pit and the inmost recesses of the ship.

He patented his invention, and charged a sum of $£_{30} 0$ for every. ship to which it was applied; but at first he met with some opposition at the Admiralty, or rather on the part of. Sir Jacob Ackworth, the then surveyor of the Navy, who put the question in reference to the foul air : "Do you know how far you are to draw it out?" The answer was: "Only six inches, for, if I can extract it ever so small a distance, the incumbent air will pass forward, of course, and cause a constant change." Mr. Sutton's patent was nevertheless adopted, and very good reports as to its effectiveness were made to the authorities; but it fell into disuse in a very few years.

From that period to the present the plan of extraction, and the plenum principle so called, have each had its own supporters; and it will be part of my duty now to inquire into their relative merits, particularly as applicable to ships of modern construction.

In a moral point of view it is quite proverbial that an attractive or drawing force is more effective than a propulsive one, and the same would appear to be the case also in the physical world. Thus it would be easier to extract 1,000 cubic fect of air from the body of a vessel than to force the same bulk of air into it.

The pressure on the contained air would be diminished in one case, so as to induce the ingress of denser air at every opening; while the pressure, though increased in the other, would not only more tardily produce the opposite effect, but favour stagnation in the very localities that would require the most efficient rentilation.

If there is no fallacy in this reasoning, we might conclude that extraction would be preferable to propulsion werc we restricted to either, which is, however, by no means likely to be the case.

Extraction may be either superficial, or deep in its effect. To be efficient, it must reach the air contained in the most confined recesses of the ship, where foul effluvia are so apt to stagnate. Superficial extraction, while there is at the same time sufficient provision for simple egress, can scarcely be of such importance.

We know that gases diffuse or commingle with a rapidity which is inversely as the square of their density. Active egress would, therefore, favour the law of diffusion without or outside the body of the vessel; while, by active ingress, or plenum ventilation, diffusion can only take place within, and even then with a disadvantage in proportion to the pressure. Moreover, in the former case the air is insensibly renewed, while in the latter cold draught is usually a concomitant.

The rentilation of circumscribed or inclosed spaces should be 
made to imitate open-air conditions as nearly as possible, so as to effect a perpetual and insensible change.

This is clearly to be brought about by free ingress and active egress more satisfactorily than by active ingress without provision for simple egress.

I have always thought that much important information respecting the theoretical part of an efficient ventilation is to be derived from the study of the respiratory process in the members of the lower creation.

Perhaps the most complex system of respiratory mechanism occurs amongst the insecta. All insects have a system of ramifying trachex, and in the greater number the respiration is aërial, the air being inhaled through a series of stigmata, which are generally situated on the sides of the rings of the abdomen. From the stigmata the air is carried by the trachex, in some insects into vesicles, from which the rest of the tracheal tubes arise; in others, into longitudinal trunks, which ramify throughout the most delicate parts of the animal. In several insects, particularly in the orlhoptera, there are distinct respiratory movements, i.e., alternate dilatation and contraction of the abdomen.

Comparing the hull of a ship with the body of an insect, and the several decks and bulk-headed spaces within the web of the vessel with the internal organisation of the animal, all the ports, hatches, and scuttles, with the air shafts, aptly represent the spiracles, or breathing pores, and the trachex, or air vessels, leading from them inwards, to be distributed to the nervous ganglia and the viscera.

The practical lesson to be drawn from this comparison is that just as every part of the insect is separately supplied with air, so should every part of a ship, as far as possible, be separately ventilated.

In animals higher in the scale the blood is aïrated by means of gills or lungs, as the case may be, occupying a definite and convenient locality, but always in some degree associated with the function of locomotion. Even in man himself increased muscular movement in quick walking or running is always attended with a corresponding acceleration of pulse and activity in the respiratory process. In the crustacea, i.e., crabs, lobsters, and shrimps, we find the gills quite near, or actually connected with, the base of the limbs, so that the activity of locomotion should induce, pari passu, the exercise of the function of respiration.

In the bivalve mollusca the lamellated branchix are in strict relationship with the energetic use of the foot, as in the common cockle (cardium) and the trigonia, or the flapping of the shells and mantle lobes, as in the genus lima, some of which are swimming members of the scallop family. Still further, amongst the various uses to which vibratile cilia are applied, we find that these organs are richly bestowed upon the respiratory apparatus of most water breathers; and swimmerets and flabella, such as we see in the crustacea, are only organs on a larger scale, wielded by muscular power for a similar purpose, namely, to bring fresh currents of water charged with vital air, to the respiratory surfaces when the locomotive function of the animal is not in exercise. We perceive then, that the 
office of the cilia and other propulsive organs in the watery medium is just what the rotatory fan or other mechanical power would be for ventilation in air.

From the iunicala and conchifera unquestionably one valuable hint is derivable, namely, that there is always provision made for the escape of the inspired water by a special channel or siphon, quite distinct from that by- which it entered, and it need scarcely be said that this very thing is a great desideratum in our modern ships. But the most important item has yet to be mentioned, namely, that in the cxamples here adduced while ingress is comparalively passive, egress is usually active, and spurting is only a further exercise of the same activity. The examples here selected, from the realm of zoology, show very clearly the essential importance of respiration in animals, and its intimate bearing on the subject of ventilation.

The rotatory fan is to ship ventilation what ciliary motion is to the gill of the oyster; and it is curious to remark that, though now so popular and important, when first tried by the inventor, Desagulier; on board H.M.S. "Kinsale," at Woolwich, it did not meet with the approval of Sir Jacob Ackworth, who condemned it without having once witnessed its operation.

- Though many improvements on the original design have been made and patented from time to time, we cannot discuss their respective merits on the present occasion, being desirous of dealing with particulars only so far as they bear upon broad principles.

The ventilation fans commonly used in H.M. ships are of three kinds, viz. :- -

I. A fan with both sides open, and commonly used for all ordinary supply purposes.

2. A fan with only one side inlet, used when the air is conveyed to the fan by a trunk, which it is not convenient to deride.

3. A fan similar to the first, but having a diaphragm in the middle, which makes it equivalent to two single-sided fans. Used chiefly for exhaust, when the trunks for conveying the air to the sides of the fan-case vary in length.

The supply fans usually fitted in the Royal Navy, vary from 3 to 6 feet in diameter, but, in cases where the escaping air would have no suitable upcast, exhaust fans are employed.

Blackman's fans; which are not centrifugal, are suitable for moving air in cabins. Two were supplied to the "Royal Sovercign" for this purpose.

Records of the result of experiments as to the volume of air in cubic feet per minute delivered by different fans, under different conditions, are both interesting and instructive. 
TABLE I.

Showing the QuaNtities of. Air Delivered. by various Fans per minute.

\begin{tabular}{|c|c|c|c|c|c|c|}
\hline \multicolumn{2}{|r|}{$\begin{array}{l}\text { Kind of Fan } \\
\text { and } \\
\text { Name of Ship. }\end{array}$} & \multirow{3}{*}{ 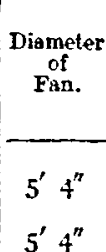 } & \multirow{2}{*}{$\mid$} & $\begin{array}{c}\text { Area } \\
\text { of } \\
\text { Delivers. }\end{array}$ & $\begin{array}{l}\text { Iangth } \\
\text { of } \\
\text { Air Trunk }\end{array}$ & $\begin{array}{l}\text { Polume of Air in } \\
\text { Cubic Feet } \\
\text { per Minute. }\end{array}$ \\
\hline ist & Rupert & & & 5 sq. ft. & $\dot{5}^{2} \mathrm{ft}$. & $(8,200)$ \\
\hline$\therefore$ & $"$ & & $5^{12}$ & $1 \%$, & " " & $9,8 \infty)$ \\
\hline 2nd & Royal Sovereign & $5^{\prime} 6^{\prime \prime}$ & 400 & $\begin{array}{l}\text { (Suction) } \\
41 / 3 \text { sq.ft. }\end{array}$ & $140 "$ & $12,27 \mathrm{a} \quad(b)$ \\
\hline 15t & $: "$ & $6^{\prime} 0^{\prime \prime}$ & 400 & $8 \quad$, & 16, & $17,500 \cdot(c)$ \\
\hline 3 rd & Howe & $3^{\prime} 0^{\prime \prime}$ & 500 & $\begin{array}{l}\text { (Suction) } \\
2 \text { sq. } \mathrm{fl} \text {. }\end{array}$ & $60 "$ & $2,900 \quad(d)$ \\
\hline " & Trafalgar & $6^{\prime} 0^{\prime \prime}$ & 200 & $7 "$ & 18, & $18,000 \quad(e)$ \\
\hline " & Impérieuse & $3^{\prime} 6^{\prime \prime}$ & 280 & $\begin{array}{l}\text { Fan inlet } \\
24 \text { sq. } \mathrm{ft} .\end{array}$ & - & $2,0+1\}(f)$ \\
\hline " & $-n$ & $"$, & 500 & $"$ & 一 & \\
\hline ", & Edinburgh : & $3^{\prime} 0^{\prime \prime}$ & 300 & & $24 " 1$ & 1,200 \\
\hline - & Experiments, Lloyds & $3^{\prime} 0^{\prime \prime}$ & $3^{60}$ & $1 / 4$, & $10 "$ & 1,390 \\
\hline - & 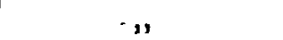 & $3^{\prime} 0^{\prime \prime}$ & 640 & $1 / 2$, & $"$, & $1,480)$ \\
\hline
\end{tabular}

ReMarks.-(See right-hand column:)

(a) This shows the advantage of a large delivery over a small one.

(b) The speed of air was taken at the inlet, the air was delivered through a long trunk with numerous louvres.

(c) The speed of air in this case was taken at the delivery.

(d) Two branches of I square foot area each. One was 8 feet nearer the fan than the other: the nearest trunk took in 1,900 cubic feet per minute, the other $\mathrm{I}$, ooo cubic feet per minute.

(e). The fan had a long and short suction: the speed of air in the long suction could not be measured; the short suction was taking $\mathbf{1}, 000$ cubic feet out of the 18,000 delivered.

$(f)$ Carpel's patent fan.

(g) This shows that, with about half the number of revolutions, nearly the same quantity of air was passed through the larger delivery.

The following list shows the relative number of supply and exhaust fans fitted in some of H.M. ships, and even a superficial review of it will make it obvious that, while the principle of extraction is not altogether ignored, the preference is given to plenum rentilation:- 
TABLE II.

Comparison of SUpply with Exhaust Fans.

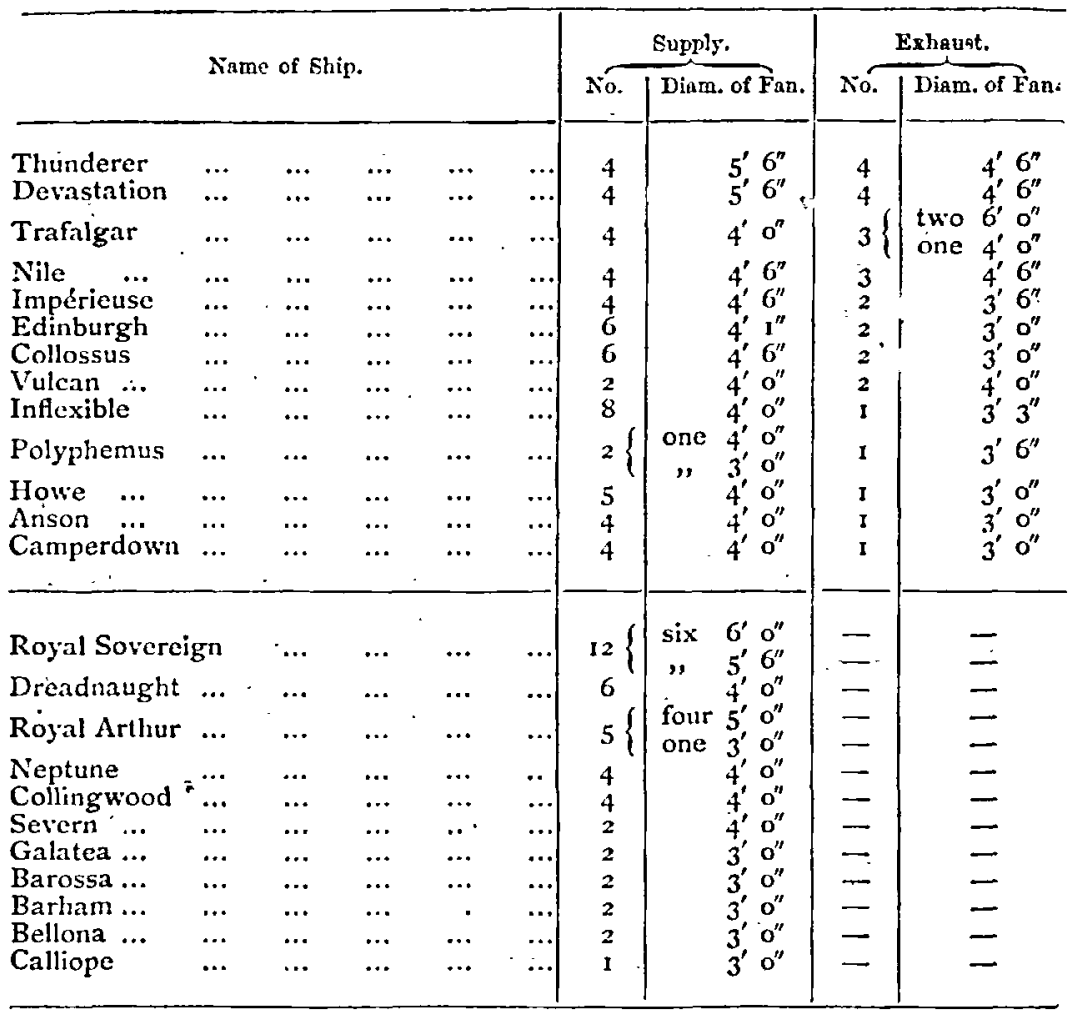

On inspection of the foregoing table it will be seen that, out of twenty-four ships, eleven-or nearly half the number-are without any mechanism for extraction; that there are five with only one exhaust fan, four with two, two with three, and the same number with four; while in every case, except the last on the list, two or more supply-fans will be found. In the "Royal Arthir". with five, the "Dreadnaught" with six, and the "Royal Sovereign" with twelve large supply fans, it is remarkable that no exhaust fans should have been found necessary. Now, I should be sorry to say that our war-ships were not efficiently ventilated; but it may be very fairly asked if, in the interest of shipping in general, the system at present so much in rogue might not be reversed with advantage, so that extraction of vitiated air from the deeper recesses of a ship should commence, and natural law complete, the cycle of a more efficient ventilation.

It is much to be regretted that ventilating requirements have hitherto been so little taken into account coincidently with the designing of ships of new construction. Ships have thus been too often built first and ventilated afterwards, so that in the effort to carry out some rational ventilating principles, constructional barriers are sure to present them- 
selves; whereas if sound ventilating provisions went hand-in-hand with construction, after-thoughts would be precluded, and making and breaking avoided.

In the old days of wooden ships, the honey-combed, inaccessible, and consequently filthy bilges have always presented a difficult problem for the hygienist to master; but if, in the first instance, they wcre made smooth and accessible, though still, if need be, the recipients of drip, thorough cleansing would be practicable, and any sensible deviations in the opposite direction would be promptly remedied.

As other nations have shared with us in bilge troubles, the sugge $f$ fions made by their hygienists may be instructive to ourselves; thus, in an excellent pamphlet by Dr. Eklund, of Stockholm, he adrocates the use of superheated steam for drying and disinfecting not only the bilges, but the openings between the timbers. He strongly advocates such an cnlargement of the bilge areas as would be sufficient to permit a middlesized man to enter them, that they might thus be easily and perfectly cleaned and dried. He also alludes to the usual flatness of the bilges, through so considerable an cxtent of the square body in modern ships, as being favourable to the permanent accumulation of water in certain parts bejond the influence of the pump-suckers. Dr. Eklund, however, adrocates the adoption of a reservoir for bilge air fore and aft upon the keelson, which would presumably take up bilge-efluvia as fast as they were formed, and thus confine them within definite limits, and at the same time permit of their speedy removal by extractive means. I cannot go the whole length with Dr. Eklund in this suggestion.

Hygienic measures, like many others, often become questions of expediency; , even admitting that certain sanitary conditions can be effected at a definite cost, it is only fair to ask, Would the benefit to be derived so far exceed the necessary: expenditure of space as to render the proposal feasible or expedient?

Many years ago I submitted a paper to the Admiralty suggesting the substitution of tubular ventilating shelf-pieces for the existing solid ones, with the view of providing for the removal of the foul air finding access to the openings between the timbers, and so frequently the source of illhealth and discomfort in wooden ships. The authorities to whom the paper was referred for judgment were good enough to say that " the plan was well conceived, and very clearly described both in principle and detail," but they could not recommend its adoption for several reasons, which, however, did not in any way challenge its practicability. I believe that one of the principal reasons was that wood was to be superseded by iron.

Experience has proved, even without reference to the anatomy of the insect, that the principal parts of a ship requiring ventilation should be furnished with separate outlets of their own. The principal parts comprehended in this proposition are:-Firstly, the bilge and orlop, for the ventilation of which the shelf-piece supporting the main deck should be tubular, with its conduits leading chiefly into the funnel or funnel casing. Secondly, the lower deck, which should be ventilated by the 
ship's 'side, with louvre openings above. Thirdly; the main deck, the ventilation of which will be much improved by means of deck air-channels fitted into the upper deck. Notwithstanding the great difference in the constructive elements, wood and iron, I have had ample means of observing that the most ordinary ingenuity can make provision for the adoption in iron ships of the same principles of ventilation that have been found effective in wooden ones.

I am quite sure that there is a great deal yet to be done in this way.

The peculiar construction of low frec-board vessels, in which all communication with the outer air is reduced to a minimum, seems to have suggested the necessity of introducing air by mechanical means to compensate for that which, under ordinary circumstances, would be permitted to enter without obstruction. The flenum principle has, without exception, been adopted in the ventilation of those ships, and under the circumstances was quite unavoidable. So, until we have fully weighed all the attending conditions, we must be cautious in our condemnation of its emplojment.

It is certain, however, that where simple or natural ventilation is more or less precluded, both the movement and the renewal of the air can be more satisfactorily effected by extraction than by propulsion, or the plenum principle.

A friend of mine in Yorkshire succeeded in patenting a scheme of extraction by heat very similar to that of Mr. Sutton, only applied to the ventilation of drains instead of ships. Some interesting particulars were developed in its practical trial, and the patentec, as usual, acquired new light as to the intrinsic nature of the difficulties with which he had to contend.

A conduit from the main drain was led into the ashpit of the inventor's mill, and the foul air was drawn up so forcibly as to keep the fan of a large anemometer in rapid revolution, indicating the extraction of thousands of cubic feet per minute. This all appeared to be satisfactory, and so it was within a certain radius, for it was found that the effect beyond this was scarcely perceptible.

It was, therefore, quite obvious that numerous centres of action must be set up (each having a range of its own), to act together and answer the purpose, cven in a very small town. This is exactly what we find with respect to ship-ventilation, which, to be efficient, must be furnished with several centres of action.

As bearing upon the effect of persistent draught, it might be mentioned that rats, which were ver plentiful in the drains before the extracting currents were established, were quite driven away from the immediate vicinity:

On the other hand, it has been found that, in ships where the contained air has been subjected to much pressure by impulsion, asthmatic persons breathe with great comfort and satisfaction; and from this we may learn that a compressed-air chamber would be a valuable addition to public hospitals, and we can comprehend more clearly the therapeutic action of such air in a portable form, under very critical circumstances. 
The Chitrman :-1 think we must have all listened with very great interest to this paper by Inspector John Macdonald. We may look upon him as the father of modern sanitary science on board ship, as he has made the subject almost his own. I hope there are some amongst those gentlemen present who will contribute to our knowledge on the subject. I think we may infer from what we have heard that the principle of the supply of pure air by artificial means is now recognised as to be applied to all new ships, according to their structural requirements, and this principle appears to have had a very fair amount of success, as will, I think, be acknowledged by those who have watched the change of ships from the old type, and have seen notwithstanding how great has been the improvement in the health of the Navy. Perhaps the most practical point for discussion would be in the direction of the advisability of supplementing the supply by the addition of artificial means of extraction of impure air; and there is also the question of bilges. I hope we may get some enlightenment upon these points.

Admiral Crevelasi : $\dot{I}$ rise, not to take part in a discussion of the paper, because it seems to me there is no controversial matter whatever in it, but $I$ wish to thank Dr. Macdonald for having brought before the public, through the medium of this Institution, such a very valuable subject as the ventilation of our: ships. Ever since I have known Dr. Macdonald he has always been. identified in my nind with the practical work which he has done in this direction. I remember in the Mediterranean many years ago our ships were ventilated on a system which Dr. Macdonald brought before the Admiral, which tended in great measure to keep the ships healthy and comfortable. I regret very much he has-told us so little as to what has been done in recent times to carry this out systematically and scientifically, but I thoroughly agree with thim that the "extractive" system is the scientific one we ought to pursue, and I regret so little has been done in this direction. I also regret that the audience here to-day has been so small; no doubt owing to the weather being so fine. There is one precaution which ought to be taken in all systems of ventilating ships, and it is this, that in case of fire we should have some ready and efficient means of shuting off the ventilation from any particular locality. That is a mere matter of detail, but still it is a matter always to be kept in view. I thank Dr. Macdonald very much indeed for having brought this subject before us, and I hope it will bear fruit.

Dr. MAcposald, on the invitation of the Chairman, added the following remarks on Respiration:-

The Respiratory Processes in the Lower Animals.

Oxygen gas is of vital importance to all the forms of animal life upon this giobe, whether marine, aquatic or terrestrial. Atmospheric air is more actively absorbed by fresh than by salt water, the capacity for it being considerably. greater in the former than in the latter.

Animals living in the open-air can, if necessary, change their immediate atmosphere by locomotion from one place to another, and animals free to move in water do virtually the same thing. But, where marine animals are fixed to the same spot as barnacles or limpets, an outgoing as weli as an incoming current must be provided for, and even with external stillness no internal stagnation is permitted to take place. In fact, extraction or egress must either alternate or be concomitant with ingress, and the condition of the animals under the circumstances may be accurately compared to that of the residents in houses or on ship board, as the case may be. Should the watery medium carrying their atmosphere, so to speak, suffer stagnation, ventilation, in the strictest sense of the term, will consist in giring motion to that medium by purely mechanical means, by vibratile cilia flabella, or by muscular power exerting pressure, or wielding flabella to effect the necessary displacement and interchange.

No satisfactory explanation has yet been given as to the intrinsic cause of ciliary motion. Like many other things in nature, we are permitted to observe it 
without really comprehending its true cause or modus operandi. The uses to which this remarkable power is applied in the animal world are so varied and important, that it would be easy to fill a volume with the abstract facts.

These minute hair-like organs, exerting an impulse in a definite direction, effect the locomotion of the infusorial animalcules, and indeed of animals of much larger size, as the turbellaria, and when thrown into action on the head lobes of the common rotifer produce a little vortex in the water, bringing fresh supplies to the mouth of the animal. The successive or sequencial impulse of the marginal cilia give rise to the appearance of rotation, and hence the popular and very appropriate name of wheel animalcules as applied to rotifera. All respiratory surfaces, whether hollow pulmonary chambers or projecting branches or gills; are invested with vibratile cilia, which materially assist the regular respiratory currents, and are perhaps intimately associated with the separation of the air contained in the water and its coincident absorption.

However extended our study may be as to the bearing of the process of respiration on the subject of ventilation, one grand lesson is clearly derivable from it, namely, that provision is always made for the perpetual and thorough removal of the currents passing over the respiratory organs, so as to preclude the possibility of stagnation or bilge-like accumulations anywhere.

Ingress and egress in a continuous line is best illustrated in the case of the tunicaries called salpians, a good example of which occurs in the genus pegea. It is fish-like in form, quite tubular, and open at both ends. Motion is given to the organism by the contraction of hoop-like muscular bands which propel it through the water, at the same time sending a strong respiratory current through the central cavity.

In ordinary fishes, the manner in which the water entering by the mouth passes first over the gills and then outwards beneath the operculum is too well known to reguire further comment here; but it may be remarked that a system of ventilation of this description would be too forcible for common purposes.

The Chamkma : I am sure we must all feel obliged to Dr. Macdonald for coming here and giving us a very excellent paper. I hope it will do some good. Of course, the direction in which he wishes change to be made is towards the extraction of impure air, and I am sorry no one else has been able to give us any information on the subject. However, I think I may assume that we all thank him for his paper.

Dr. Macdonald: I am much obliged to you. I am very glad to have brought the subject forward, and thank you for the kind manner in which my paper has been received. . Of course, the matter of ventilation is one which has been dealt with in various ways, but I am very glad that it has been so far "aired"; and it will, no doubt, benefit by being brought forward at this Institution. 